\title{
Utilização de fosfatos comerciais para frangos de corte na fase inicial
}

\author{
Livya Stefane Borges de Queiroz ${ }^{(1)}$, Antonio Gilberto Bertechini ${ }^{(1)}$, Paulo Borges Rodrigues ${ }^{(1)}$ \\ e Mário César Guerreiro ${ }^{(1)}$
}

(1)Universidade Federal de Lavras, Departamento de Zootecnia, Caixa Postal 3037, CEP 37200-000 Lavras, MG. E-mail: livyazoot@yahoo.com.br, bertechini@ufla.br, pborges@ufla.br, guerrero@ufla.br

\begin{abstract}
Resumo - O objetivo deste trabalho foi avaliar o desempenho e a mineralização óssea de frangos de corte, na fase de 1-21 dias de idade, e a biodisponibilidade de fósforo de fosfatos comerciais utilizados na alimentação de frangos de corte. Mil e oito pintos machos de um dia de idade foram distribuídos em 14 tratamentos, com 6 repetições de 12 aves cada, em delineamento inteiramente ao acaso. Os fosfatos avaliados foram o defluorizado, monocálcico $\mathrm{B}$, bicálcico $\mathrm{A}$, bicálcico $\mathrm{B}$ e bicálcico $\mathrm{C}$, com dois níveis de fósforo disponível $(0,30$ e $0,40 \%$ ). Foi adotada a técnica da abscissa e o fosfato monocálcico A como padrão (valor $100 \%$ ), com quatro níveis de fósforo disponível: $0,25,0,35,0,45$ e $0,55 \%$ para o cálculo da biodisponibilidade relativa. Todos os fosfatos com $0,40 \%$ do fósforo disponível proporcionaram às aves ganho de peso semelhante. Houve maior mineralização óssea das aves com o fosfato monocálcico B, comparado ao fosfato defluorizado. As fontes de fósforo apresentaram pequenas diferenças nos valores de biodisponibilidade relativa, com melhores resultados quanto ao monocálcico B e com maior sensibilidade de resposta da variável cinzas ósseas, em relação ao ganho de peso.
\end{abstract}

Termos para indexação: biodisponibilidade, cinzas ósseas, desempenho, fontes de fósforo.

\section{Utilization of commercial phosphates for broilers in the starter phase}

\begin{abstract}
The objective of this work was to evaluate the performance and the bone mineralization of broilers, at 1 to 21 days of age, and the bioavailability of phosphorus in commercial phosphates utilized in the broilers feeding. One thousand and eight male chickens of one day old were distributed in a completely randomized design, in fourteen treatments, with six replications of twelve birds each. Phosphates evaluated were: defluorinated phosphate, monocalcium B, dicalcium A, dicalcium B and dicalcium C, with two levels of available phosphorus $(0.30$ and $0.40 \%)$. For the evaluation of the relative bioavailability, the abscissa technique was used, and the monocalcium A phosphate was taken as standard (value of $100 \%$ ), with four levels of available phosphorus: $0.25,0.35,0.45$ and $0.55 \%$. All the phosphates with $0.40 \%$ of available phosphorus levels propitiated similar weight gain to broilers. The monocalcium B resulted in higher bone mineralization of broilers than the defluorinated phosphate. The different phosphorus sources presented few differences in the values of relative bioavailability of phosphorus, with better results for the monocalcium B and with higher sensibility response for bone ashes than for body weight gain.
\end{abstract}

Index terms: bioavailability, bone ash, performance, phosphorous sources.

\section{Introdução}

O sucesso da atividade avícola é resultado do equilíbrio entre lucro e produção, sendo a alimentação responsável por 70 a $80 \%$ do custo total, o que justifica o elevado número de pesquisas desenvolvidas na área.

A baixa disponibilidade de $\mathrm{P}$ nos alimentos vegetais usados nas rações animais torna necessária a suplementação desse mineral a partir de fontes, como o fosfato bicálcico, que onera o custo de produção, uma vez que o fósforo inorgânico é, entre os elementos minerais, o mais caro (Nunes et al., 2001). A tendência de se utilizar fontes alternativas ao uso de ingredientes de origem animal, como a farinha de carne e osso, destaca os fosfatos como o principal meio de suplementação de P na alimentação de frangos de corte.

Diferentes técnicas são utilizadas para determinar a quantidade de nutrientes que o animal requer. A biodisponibilidade, definida por Duarte et al. (2003) como a proporção ou percentagem do nutriente consumido que pode ser absorvida pelo intestino, 
tornando-se disponível para uso no metabolismo ou para estocagem nos tecidos animais.

A biodisponibilidade do $\mathrm{P}$ nas diferentes fontes inorgânicas pode variar, pois a origem do material e o processamento empregado na sua produção industrial são determinantes na caracterização dos fosfatos utilizados na alimentação animal.

Estão disponíveis no mercado, para uso em rações, diversas fontes de $\mathrm{P}$ com teores variados, como os fosfatos bicálcicos, monocálcicos, de rocha defluorizados, monoamônio (MAP) e tricálcico, entre outras fontes.

Fontes alternativas de $\mathrm{P}$ podem levar a utilização de ingredientes nas rações com presença de contaminantes e disponibilidade de P reduzida. Fosfatos de rocha, bem como fosfatos agrícolas, apesar do preço reduzido, apresentam menor biodisponibilidade de $\mathrm{P}$ e elevados teores de flúor (Fernandes et al., 1999). Porém, Garcia et al. (2006) relata que o fosfato tricálcico defluorizado (FTD) pode ser utilizado satisfatoriamente em dietas de pintos durante a fase pré-inicial (1 a 8 dias) e inicial (9 a 15 dias), não havendo diferenças maiores que 10\% de biodisponibilidade relativa de $\mathrm{P}$ entre os fosfatos bicálcico e tricálcico defluorizado.

As diversas fontes utilizadas (Cortelazzi, 2006), a metodologia empregada para obtenção dos resultados (Yan et al., 2005) e o processamento industrial (Butolo, 2002) são fontes de variação limitantes para o conhecimento das fontes de $\mathrm{P}$ para uso na alimentação animal.

Em estudo conduzido por Cortelazzi (2006), foram avaliados fosfato bicálcico produzidos nos EUA e no Brasil, monobicálcico e monossódico, em que foi utilizado o fosfato bicálcico quimicamente puro como padrão, tendo sido constatado maior valor de biodisponibilidade relativa de $\mathrm{P}$ para $\mathrm{O}$ fosfato monossódico (108\%), calculados a partir do peso das cinzas dos dedos médio das aves aos 21 dias.

O objetivo deste trabalho foi avaliar a biodisponibilidade relativa de $\mathrm{P}$ de fosfatos comerciais, o desempenho e a mineralização óssea de frangos de corte na fase de 1-21 dias de idade, submetidos às rações com diferentes fontes de $\mathrm{P}$.

\section{Material e Métodos}

O experimento foi conduzido no Centro de Pesquisa em Tecnologia Avícola (CPTA), localizado na BR 265,
Km 144, na cidade de Lavras, MG, no período de agosto a setembro de 2006.

Foram utilizados 1.008 pintos de corte machos de um dia, linhagem Cobb-500, com peso médio inicial de $42,5 \mathrm{~g}$. O delineamento experimental foi o inteiramente casualizado, com 6 repetições e 12 aves por unidade experimental.

Para o estudo das fontes de P, utilizou-se 720 aves com 10 tratamentos em esquema fatorial $5 \times 2$ ( 5 fontes de fósforo x 2 níveis de fósforo disponível), sendo estudados os fosfatos defluorizado (FTD), monocálcico B (FMC-B), bicálcico A (FB-A), bicálcico B (FB-B) e bicálcico $\mathrm{C}$ (FB-C), com dois níveis de Pd: 0,30 e $0,40 \%$.

Para a determinação da biodisponibilidade relativa do $\mathrm{P}$ das fontes estudadas, foram utilizadas 288 aves com o fosfato monocálcico A (FMC-A) como padrão (valor $100 \%$ ), com quatro níveis de Pd: $0,25,0,35$, 0,45 e $0,55 \%$.

As rações experimentais foram formuladas de acordo com Rostagno et al. (2005), para a fase de 1-21 dias de idade, e tiveram a seguinte composição: $56 \%$ de milho, $36,9 \%$ de farelo de soja, $3,13 \%$ de óleo de soja, $0,5 \%$ de sal, $0,1 \%$ de suplemento mineral (60 mg de $\mathrm{Zn}, 30 \mathrm{mg}$ de Fe, $9 \mathrm{mg}$ de $\mathrm{Cu}$, $60 \mathrm{mg}$ de Mn e $1 \mathrm{mg}$ de I, por quilograma de ração), $0,10 \%$ de suplemento vitamínico (12.000 UI vitamina A, 2.200 UI de vitamina D3, $30 \mathrm{mg}$ de vitamina E, 2,5 mg de vitamina $\mathrm{K} 3,2,2 \mathrm{mg}$ de vitamina $\mathrm{B} 1,6 \mathrm{mg}$ de vitamina $\mathrm{B} 2,3,3 \mathrm{mg}$ de vitamina $\mathrm{B} 6$, $16 \mu \mathrm{g}$ de vitamina B12, $0,11 \mathrm{mg}$ de biotina, $1 \mathrm{mg}$ de ácido fólico, $13 \mathrm{mg}$ de ácido pantotênico, $53 \mathrm{mg}$ de nicotinamida e $120 \mathrm{mg}$ de antioxidante BHT, por quilograma de ração), 0,26\% de DL-metionina (99\%), $0,17 \%$ de L-lisina $(78 \%), 0,06 \%$ de anticoccidiano (maduramicina - $10 \mathrm{~g} \mathrm{~kg}^{-1}$ de produto), $0,02 \%$ de antibiótico (bacitracina de zinco $10 \%$ ) e $0,03 \%$ de cloreto de colina $70 \%$. Os demais componentes estão listados na Tabela 1. A composição calculada dessas rações foi: $3.000 \mathrm{kcal} \mathrm{kg}^{-1}$ de energia metabolizável, $21 \%$ de proteína bruta, $0,9 \%$ de cálcio, $1,19 \%$ de lisina digestível, $0,55 \%$ de metionina digestível, $0,84 \%$ de metionina digestível + cistina digestível e $0,22 \%$ de sódio.

A composição das rações experimentais do FMC-A (fosfato padrão) foi: $53,6 \%$ de milho, $37,3 \%$ de farelo de soja, 3,96\% de óleo de soja, $0,50 \%$ de sal, $0,10 \%$ de suplemento mineral (60 mg de Zn, $30 \mathrm{mg}$ de Fe, 
$9 \mathrm{mg}$ de $\mathrm{Cu}, 60 \mathrm{mg}$ de $\mathrm{Mn}$ e $1 \mathrm{mg}$ de I, por quilograma de ração), $0,1 \%$ de suplemento vitamínico (12.000 UI de vitamina A, 2.200 UI de vitamina D3, $30 \mathrm{mg}$ de vitamina $\mathrm{E}, 2,5 \mathrm{mg}$ de vitamina $\mathrm{K} 3,2,2 \mathrm{mg}$ de vitamina $\mathrm{B} 1,6 \mathrm{mg}$ de vitamina B2, 3,3 mg de vitamina B6, $16 \mu \mathrm{g}$ de vitamina B12, 0,11 mg de biotina, $1 \mathrm{mg}$ de ácido fólico, $13 \mathrm{mg}$ de ácido pantotênico, $53 \mathrm{mg}$ de nicotinamida e $120 \mathrm{mg}$ de antioxidante BHT, por quilograma de ração), $0,26 \%$ de DL-metionina 99\%, 0,16\% de L-lisina 78\%, 0,06\% de anticoccidiano (maduramicina - $10 \mathrm{~g} \mathrm{~kg}^{-1}$ produto), $0,03 \%$ de antibiótico (bacitracina de zinco $10 \%$ ) $, 0,03 \%$ de cloreto de colina $70 \%$ e $1,30 \%$ de caulim. Os demais componentes estão listados na Tabela 2. A composição calculada dessas rações foi idêntica à das demais rações experimentais.

$\mathrm{O}$ valor de biodisponibilidade relativa dos fosfatos foi obtido pelo consumo de fósforo disponível (CPd) das aves alimentadas com as rações com a fonte-teste e sua resposta, por meio das variáveis ganho de peso e cinzas ósseas, na equação da fonte-padrão. A relação entre o valor observado e o estimado foi a biodisponibilidade relativa obtida. O método empregado foi o da abscissa, de acordo com Gillis et al. (1954).

O desempenho das aves foi avaliado pelo consumo de ração, ganho de peso e conversão alimentar de 1-21 dias e, ao final do período experimental, foram abatidas duas aves por parcela de peso médio da unidade experimental, tendo sido retiradas as tíbias para posterior análise de cinzas ósseas.

As temperaturas máxima e mínima foram anotadas, diariamente, às $16 \mathrm{~h}$, por meio de um termoigrômetro, localizado na parte central do galpão, e as médias máxima e mínima obtidas foram de $27,6 \mathrm{e} 19,5^{\circ} \mathrm{C}$, respectivamente, e a umidade relativa média de $68,5 \%$. O programa de iluminação adotado foi o de 24 horas de luz constante.

As análises estatísticas dos dados foram realizadas pelo SISVAR, descrito por Ferreira (2000), tendo sido utilizados o teste de SNK, a 5\% de probabilidade, para comparação das fontes de $\mathrm{P}$, e o teste $\mathrm{F}$ para os níveis de
P utilizados. Os dados de ganho de peso e cinzas ósseas das aves submetidas às rações com o fosfato padrão (fosfato monocálcico A) como fonte de fósforo, foram submetidos à análise de regressão para a obtenção da curva padrão.

\section{Resultados e Discussão}

Os resultados referentes ao desempenho e cinzas ósseas de frangos de corte na fase de 1-21 dias de idade, submetidos à ração com o fosfato monocálcico $\mathrm{A}$ (FMC-A) com diferentes níveis de fósforo, estão apresentados na Tabela 3.

Por meio da análise de regressão, pode-se observar efeito quadrático $(\mathrm{p} \leq 0,01)$ dos níveis de Pd sobre o desempenho das aves, com valores máximos de consumo de ração (CR) e de ganho de peso (GP) com a utilização do nível de 0,44\% de Pd na ração, e melhor conversão alimentar (CA) com o nível de $0,45 \%$ de Pd. Houve efeito linear $(p \leq 0,05)$ para a percentagem de cinzas ósseas na tíbia, com maior mineralização óssea para o maior nível de Pd estudado $(0,55 \%)$.

Ao utilizar o FMC-A (padrão) como fonte de $\mathrm{P}$, os valores de $\mathrm{Pd}$ apontados para otimizar o desempenho das aves foram semelhantes aos encontrados na literatura. Segundo Rostagno et al. (2005), a exigência nutricional de Pd para frangos de corte é de $0,466 \%$, de $1-7$ dias, e de 0,439\% de Pd, de 8-21 dias de idade. Runho et al. (2001) sugeriram o valor de $0,450 \%$ de Pd como o ideal para essa fase ao avaliar seis níveis de $\mathrm{Pd}$, em rações de frango de corte, na fase de crescimento (1-21 dias), tendo utilizado como fonte o fosfato bicálcico.

Os valores apontados pela análise de regressão para otimizar as características de desempenho não são os mesmos indicados para máxima mineralização óssea. Esse fato foi verificado também por Gomes et al. (1994), que trabalharam com frangos de corte na fase de crescimento e encontraram maior valor de exigência de Pd para maximizar o desenvolvimento dos ossos do que para otimizar o ganho de peso.

Tabela 1. Composição percentual e níveis nutricionais calculados das rações experimentais.

\begin{tabular}{|c|c|c|c|c|c|c|c|c|c|c|}
\hline \multirow[t]{3}{*}{ Ingredientes } & \multicolumn{10}{|c|}{$\operatorname{Rações~}^{(1)}$} \\
\hline & \multicolumn{2}{|c|}{ FMC-B } & \multicolumn{2}{|c|}{ FTD } & \multicolumn{2}{|c|}{ FB-A } & \multicolumn{2}{|c|}{ FB-B } & \multicolumn{2}{|c|}{ FB-C } \\
\hline & $0,3 \% \mathrm{Pd}$ & $0,4 \% \mathrm{Pd}$ & $0,3 \% \mathrm{Pd}$ & $0,4 \% \mathrm{Pd}$ & $0,3 \% \mathrm{Pd}$ & $0,4 \% \mathrm{Pd}$ & $0,3 \% \mathrm{Pd}$ & $0,4 \% \mathrm{Pd}$ & $0,3 \% \mathrm{Pd}$ & $0,4 \% \mathrm{Pd}$ \\
\hline Fosfato (\%) & 0,95 & 1,44 & 1,05 & 1,60 & 1,02 & 1,56 & 1,05 & 1,61 & 1,05 & 1,61 \\
\hline Calcário calcítico (\%) & 1,52 & 1,23 & 1,22 & 0,76 & 0,46 & 1,12 & 1,43 & 1,09 & 1,43 & 1,09 \\
\hline Caulim $(\%)$ & 0,30 & 0,10 & 0,50 & 0,41 & 1,30 & 0,09 & 0,29 & 0,07 & 0,29 & 0,07 \\
\hline
\end{tabular}

${ }^{(1)}$ FMC-B, fosfato monocálcico B; FTD, fosfato defluorizado; FB-A, fosfato bicálcico A; FB-B, fosfato bicálcico B; FB-C, fosfato bicálcico C; Pd, fósforo disponível. 
Os resultados referentes ao desempenho de frangos de corte, submetidos às rações com os fosfatos-teste, com dois níveis de Pd, estão apresentados na Tabela 4.

Houve interação significativa $(p \leq 0,05)$ entre os níveis e fontes de P estudados. Independentemente da fonte utilizada, os valores de consumo de ração e ganho de peso das aves que receberam os tratamentos com $0,40 \%$ de Pd foram superiores, quando comparadas com o nível de $0,30 \%$ de Pd. Nos tratamentos com $0,40 \%$ de Pd, foram verificados menores valores de consumo de ração para as aves alimentadas com a ração com o FTD como fonte de P. Porém, pode-se observar que, com a utilização das diferentes fontes de $\mathrm{P}$ estudadas, o ganho de peso das aves que receberam os tratamentos com $0,40 \%$ de Pd foi semelhante, o que resultou em melhor conversão alimentar para as aves alimentadas com a ração contendo o FTD como fonte suplementar de P. Isto demonstra a eficiência das fontes estudadas em promover resultados de ganho de peso semelhantes entre as aves, desde que alimentadas com rações com o nível de Pd adequado e próximo ao recomendado pela literatura.

Garzillo (1996) evidenciou o papel do P no controle da ingestão alimentar, em que, baixos níveis de P reduziu o metabolismo basal e o apetite. Esse fato também foi observado por Cortelazzi (2006), que encontrou aumento de $3,82 \%$ no ganho de peso nas aves alimentadas com as rações suplementadas com $0,16 \%$ de $\mathrm{P}(0,56 \% \mathrm{P}$ total $)$, em relação às que consumiram dietas suplementadas com $0,08 \%$ de $\mathrm{P}(0,48 \% \mathrm{P}$ total $)$, independentemente da fonte de $\mathrm{P}$ avaliada.

Ao estudar diferentes fontes de P na alimentação de frangos de corte utilizando o fosfato bicálcico como padrão, Furtado (1991) encontrou menores valores de

Tabela 2. Composição percentual das rações experimentais do fosfato monocálcico A (fosfato padrão).

\begin{tabular}{llccc}
\hline Ingredientes & \multicolumn{4}{c}{ Percentagem de fósforo disponível } \\
\cline { 2 - 5 } & 0,25 & 0,35 & 0,45 & 0,55 \\
\hline Fosfato (\%) & 0,66 & 1,14 & 1,62 & 2,09 \\
Calcário calcítico (\%) & 1,80 & 1,60 & 1,40 & 1,19 \\
\hline
\end{tabular}

biodisponibilidade de $\mathrm{P}$ para os fosfatos semi-defluorizado $(62,43 \%)$ e para o fosfato natural de Patos de Minas $(42,50 \%)$.

Os resultados de cinzas ósseas das aves, de acordo com as diferentes fontes de $\mathrm{P}$, com dois níveis de Pd, estão apresentados na Tabela 5.

A média geral para os fosfatos-teste foi de $55,63 \%$ de cinzas na tíbia, e houve diferença significativas $(\mathrm{p} \leq 0,05)$ entre as fontes estudadas. Maior valor de cinzas ósseas foi obtido para a fonte FMC-B, tendo sido superior apenas à fonte FTD. As demais fontes estudadas apresentaram teores semelhantes de cinzas ósseas entre si e à fonte FMC-B.

Quando comparado ao FMC-B, o defluorizado apresentou menor $(\mathrm{p}<0,05)$ média de percentagem de cinzas na tíbia. Esses resultados são atribuídos ao menor consumo de ração observado nas aves submetidas ao tratamento com o FTD como fonte suplementar de P, com conseqüente inferioridade na deposição óssea devido ao menor consumo de ração.

$\mathrm{O}$ fosfato monocálcico é indicado pela literatura como uma fonte de alta disponibilidade de $\mathrm{P}$, porém representa maior custo de suplementação de $P$ quando comparado a outras fontes utilizadas em dietas para frangos de corte.

Cortelazzi (2006), ao utilizar diferentes fosfatos bicálcicos na ração de frangos de corte, observou maiores pesos de cinzas na tíbia das aves alimentadas com o fosfato bicálcico padrão do que as aves alimentadas com dietas com fosfato bicálcico IMC, bicálcico PCS (EUA), bicálcico PCS (Brasil) e bicálcico Serrana.

$\mathrm{Na}$ Tabela 6 encontra-se as equações de regressão, com as cinzas da tíbia aos 21 dias e o ganho de peso das aves na fase de 1-21 dias como variáveis resposta (y) em função do consumo de $\mathrm{P}$ disponível (x), das rações de fosfato monocálcico $\mathrm{A}$, com diferentes níveis de $\mathrm{P}$ disponível.

Nas Tabelas 7 e 8 encontram-se os resultados de biodisponibilidade relativa de fósforo (BRP) dos fosfatos estudados, tomando-se por base a biodisponibilidade do fósforo do FMC-Ae as cinzas da tíbia aos 21 dias e o ganho

Tabela 3. Desempenho e cinzas ósseas de frangos de corte na fase inicial (1-21 dias de idade), alimentados com rações com fosfato padrão (monocálcico A), com diferentes níveis de fósforo disponível.

\begin{tabular}{lcccrr}
\hline Características avaliadas $^{(1)}$ & \multicolumn{3}{c}{ Nível de fósforo disponível (\%) } & \multicolumn{1}{c}{ CV (\%) } \\
\cline { 2 - 4 } & 0,25 & 0,35 & 0,45 & 0,55 & 1.272 \\
Consumo de ração (g) & 1.227 & 1.268 & 1.329 & 811 & 1.274 \\
Ganho de peso (g) & 759 & 812 & 841 & 806 & 1,91 \\
Conversão alimentar (g/g) & 1,62 & 1,56 & 1,58 & 1,13 & 1,58 \\
Cinzas ósseas (\%) & 54,59 & 55,71 & 56,93 & 57,09 & 56,08 \\
\hline
\end{tabular}

${ }^{(1)}$ Consumo de ração $(p \leq 0,01)=837,33+2141,89 x-2434,37 x^{2}, R^{2}=81,73 \%$; ganho de peso $(p \leq 0,01)=424,61+1851,69 x-2082,50 x^{2}, R^{2}=98,27 \%$; conversão alimentar $(\mathrm{p} \leq 0,05)=1,79-1,02 \mathrm{x}+1,13 \mathrm{x}^{2}, \mathrm{R}^{2}=68,69 \%$; cinzas ósseas $(\mathrm{p} \leq 0,05)=52,57+0,874 \mathrm{x}, \mathrm{R}^{2}=92,88 \%$. 
de peso das aves na fase de 1-21 dias como variáveis resposta, respectivamente. Para a variável ganho de peso foi utilizado para o cálculo somente a fase linear de resposta, com três níveis de Pd avaliados.

Ao se utilizar o FMC-A como padrão e as cinzas ósseas como variável resposta, foram observados maiores valores de biodisponibilidade relativa para o FMC-B $(102,18 \%)$ e menor valor para o FTD $(98,23 \%)$. Esses resultados

Tabela 4. Desempenho de frangos de corte na fase inicial (1-21 dias de idade) alimentados com rações com diferentes fontes de fósforo, com dois níveis de fósforo disponível (Pd).

\begin{tabular}{lcclc}
\hline Fosfato $^{(1)}$ & $\begin{array}{c}\text { Nível de } \\
\mathrm{Pd}(\%)\end{array}$ & $\begin{array}{c}\text { Consumo de } \\
\text { ração }^{(2)}\left(\mathrm{g} \mathrm{ave}^{-1}\right)\end{array}$ & $\begin{array}{c}\text { Ganho de } \\
\text { peso }^{(2)}\left(\mathrm{g} \mathrm{ave}^{-1}\right)\end{array}$ & $\begin{array}{c}\text { Conversão } \\
\text { alimentar }^{(3)}\left(\mathrm{g} \mathrm{g}^{-1}\right)\end{array}$ \\
\hline FTD & 0,3 & $1.183 \mathrm{Bc}$ & $772 \mathrm{Bab}$ & 1,53 \\
& 0,4 & $1.214 \mathrm{Ab}$ & $819 \mathrm{Aa}$ & 1,48 \\
\hline Média & & 1.199 & 796 & $1,51 \mathrm{~A}$ \\
\hline FMC-B & 0,3 & $1.215 \mathrm{Bb}$ & $746 \mathrm{Bc}$ & 1,63 \\
& 0,4 & $1.294 \mathrm{Aa}$ & $833 \mathrm{Aa}$ & 1,55 \\
\hline Média & & 1.255 & 790 & $1,59 \mathrm{C}$ \\
\hline FB-A & 0,3 & $1.248 \mathrm{Ba}$ & $784 \mathrm{Ba}$ & 1,59 \\
& 0,4 & $1.293 \mathrm{Aa}$ & $816 \mathrm{Aa}$ & 1,58 \\
\hline Média & & 1.271 & 800 & $1,59 \mathrm{C}$ \\
\hline FB-B & 0,3 & $1.180 \mathrm{Bc}$ & $749 \mathrm{Bc}$ & 1,58 \\
& 0,4 & $1.263 \mathrm{Aa}$ & $829 \mathrm{Aa}$ & 1,53 \\
\hline Média & & 1.222 & 789 & $1,55 \mathrm{~B}$ \\
\hline FB-C & 0,3 & $1.208 \mathrm{Bbc}$ & $760 \mathrm{Bbc}$ & 1,59 \\
& 0,4 & $1.274 \mathrm{Aa}$ & $817 \mathrm{Aa}$ & 1,56 \\
\hline Média & & 1.241 & 789 & $1,58 \mathrm{BC}$ \\
\hline CV $(\%)$ & & 1,76 & 1,86 & 2,20 \\
\hline
\end{tabular}

${ }^{(1)}$ FTD, fosfato defluorizado; FMC-B, fosfato monocálcico B; FB-A, fosfato bicálcico A; FB-B, fosfato bicálcico B; FB-C, fosfato bicálcico C. ${ }^{(2)}$ Desdobramento da interação: letras minúsculas diferentes em cada nível de $\mathrm{Pd}$ (entre fosfatos) e maiúsculas diferentes em cada fosfato, na coluna, diferem pelo teste de SNK, a 5\% de probabilidade. ${ }^{(3)}$ Médias com letras maiúsculas na coluna diferem pelo teste de SNK, a $1 \%$ de probabilidade.

Tabela 5. Cinzas ósseas de frangos de corte de 1-21 dias de idade, alimentados com rações com diferentes fosfatos-teste com dois níveis de fósforo disponível $(\mathrm{Pd})^{(1)}$.

\begin{tabular}{lcccccc}
\hline Pd $(\%)$ & \multicolumn{5}{c}{ Fosfato $^{(2)}$} & Média \\
\cline { 2 - 6 } & FTD & FMC-B & FB-A & FB-B & FB-C & \\
\hline 0,3 & 53,02 & 55,97 & 55,87 & 54,89 & 53,35 & $54,62 \mathrm{~B}$ \\
0,4 & 55,97 & 57,68 & 56,75 & 55,87 & 56,97 & $56,65 \mathrm{~A}$ \\
\hline Média & $54,50 \mathrm{~B}$ & $56,82 \mathrm{~A}$ & $56,31 \mathrm{AB}$ & $55,38 \mathrm{AB}$ & $55,16 \mathrm{AB}$ & 55,63 \\
\hline
\end{tabular}

${ }^{(1)}$ Médias com distintas letras maiúsculas na coluna diferem entre si pelo teste de SNK, a $5 \%$ de probabilidade; o coeficiente de variação foi de 2,20\%. ${ }^{(2)}$ FTD, fosfato defluorizado; FMC-B, fosfato monocálcico B; FB-A, fosfato bicálcico A; FB-B, fosfato bicálcico B; FB-C, fosfato bicálcico C. encontrados se devem ao fato de que o consumo de ração das aves, alimentadas com os tratamentos contendo o FTD como fonte de P foi menor, levando a menor ingestão de $\mathrm{Pd}$ e menor percentagem de cinzas ósseas na tíbia, o que diminui os valores de biodisponibilidade.

Por meio do ganho de peso, os fosfatos apresentaram valores de biodisponibilidade relativa de $\mathrm{P}$ próximos entre si, tendo sido pouco inferiores ao padrão utilizado. Esses dados demonstram que a variável cinzas ósseas apresenta maior sensibilidade de resposta quando se faz comparação entre as fontes de P. Resultados esses também evidenciados em trabalho de Lima et al. (1997), que ao avaliar a biodisponibilidade relativa de fósforo de sete fosfatos bicálcicos comerciais, cinco de origem brasileira e dois norte americanos, encontraram valores de biodisponibilidade de 80,32 a $107,34 \%$, nas cinzas ósseas, e de 97,07 a $110,41 \%$ ao se utilizar o ganho de peso como variável resposta. Fernandes et al. (1999) confirmam essa diferença nos resultados encontrados, utilizando-se diferentes variáveis resposta nos estudos de biodisponibilidade relativa de $P$.

Borges et al. (1997), ao trabalhar com diferentes fontes de $\mathrm{P}$ na alimentação de frangos de corte, tendo utilizado o fosfato bicálcico como padrão, encontraram os valores de 82,8 e $67,5 \%$, para os fosfatos semi-defluorizado e natural de Patos de Minas, respectivamente. Segundo Furtado (1991), com o fosfato bicálcico como padrão, os valores de biodisponibilidade de $\mathrm{P}$ para os fosfatos semidefluorizado e natural de Patos de Minas são de 62,43 e $42,50 \%$, respectivamente.

As discordâncias nos valores de biodisponibilidade relativa entre fosfatos igualmente classificados (bicálcicos, monocálcicos etc), mas de marcas comerciais diferentes, demonstram a diferenciação na origem e no processo de fabricação deles, além da variabilidade dos padrões adotados, já que eles são considerados com biodisponibilidade $100 \%$.

Tabela 6. Equações de regressão da biodisponibilidade do fósforo disponível (Pd), tendo as cinzas da tíbia aos 21 dias e o ganho de peso das aves na fase de 1-21 dias como variáveis resposta (y), em função do consumo de P disponível (x) das rações de fosfato monocálcico A, com diferentes níveis de P disponível.

\begin{tabular}{|c|c|c|c|c|c|c|}
\hline \multirow[t]{2}{*}{ Variável } & \multicolumn{4}{|c|}{ P disponível na ração } & \multirow[t]{2}{*}{ Equação } & \multirow[t]{2}{*}{$\mathrm{R}^{2}(\%)$} \\
\hline & 0,25 & 0,35 & 0,45 & 0,55 & & \\
\hline Consumo de $\mathrm{P}\left(\mathrm{g}_{\mathrm{ave}}{ }^{-1} \mathrm{dia}^{-1}\right)$ & 3,07 & 4,44 & 5,98 & 7,00 & & \\
\hline Cinzas $(\%)$ & 54,59 & 55,70 & 56,93 & 57,09 & $y=52,672+0,665 x$ & 98,08 \\
\hline Ganho de peso $\left(\mathrm{g} \mathrm{ave}^{-1} \mathrm{dia}^{-1}\right)$ & 759 & 812 & 841 & - & $y=678,16+27,99 x$ & 97,98 \\
\hline
\end{tabular}


Tabela 7. Biodisponibilidade relativa do fósforo disponível (Pd) dos fosfatos estudados, tomando-se por base a biodisponibilidade do $\mathrm{P}$ disponível $(\mathrm{Pd})$ consumido do fosfato monocálcico $\mathrm{A}$, com as cinzas das tíbias de frangos de corte aos 21 dias de idade como variável resposta.

\begin{tabular}{|c|c|c|c|c|}
\hline $\begin{array}{l}\text { Nível de } \\
\text { Pd (\%) }\end{array}$ & $\begin{array}{l}\text { Consumo de } \\
\mathrm{Pd}\left(\mathrm{g} \mathrm{ave}^{-1}\right)\end{array}$ & $\begin{array}{c}\text { Cinzas } \\
\text { observada }(\%)\end{array}$ & $\begin{array}{c}\text { Cinzas } \\
\text { estimada }(\%)\end{array}$ & $\begin{array}{l}\text { Biodisponibilidade } \\
\text { relativa }(\%)\end{array}$ \\
\hline & \multicolumn{4}{|c|}{ Fosfato defluorizado } \\
\hline 0,3 & 3,55 & 53,02 & 55,03 & \multirow{2}{*}{98,23} \\
\hline 0,4 & 4,86 & 55,97 & 55,90 & \\
\hline & \multicolumn{4}{|c|}{ Fosfato monocálcico B } \\
\hline 0,3 & 3,65 & 55,97 & 55,10 & \multirow{2}{*}{102,18} \\
\hline 0,4 & 5,18 & 57,68 & 56,12 & \\
\hline & \multicolumn{4}{|c|}{ Fosfato bicálcico A } \\
\hline 0,3 & 3,74 & 55,87 & 55,16 & \multirow{2}{*}{101,20} \\
\hline 0,4 & 5,18 & 56,75 & 56,12 & \\
\hline & \multicolumn{4}{|c|}{ Fosfato bicálcico B } \\
\hline 0,3 & 3,54 & 54,89 & 55,03 & \multirow{2}{*}{99,73} \\
\hline 0,4 & 5,05 & 55,87 & 56,03 & \\
\hline & \multicolumn{4}{|c|}{ Fosfato bicálcico $\mathrm{C}$} \\
\hline 0,3 & 3,62 & 53,35 & 55,08 & \multirow{2}{*}{99,24} \\
\hline 0,4 & 5,10 & 56,97 & 56,06 & \\
\hline
\end{tabular}

Tabela 8. Biodisponibilidade relativa do fósforo disponível (Pd) dos fosfatos estudados, tomando-se por base a biodisponibilidade do $\mathrm{P}$ disponível ( $\mathrm{Pd}$ ) consumido do fosfato monocálcico A, com o ganho de peso de frangos de corte na fase inicial (1-21 dias de idade) como variável resposta.

\begin{tabular}{|c|c|c|c|c|}
\hline $\begin{array}{l}\text { Nível de } \\
\text { Pd (\%) }\end{array}$ & $\begin{array}{l}\text { Consumo de } \\
\operatorname{Pd}\left(\mathrm{g} \mathrm{ave}^{-1}\right)\end{array}$ & $\begin{array}{c}\text { Ganho de peso } \\
\text { observado } \\
\left(\mathrm{g}_{\text {ave }}{ }^{-1}\right)\end{array}$ & $\begin{array}{c}\text { Ganho de peso } \\
\text { estimado } \\
\left.\left(\mathrm{g}_{\mathrm{ave}}\right)^{-1}\right)\end{array}$ & $\begin{array}{c}\text { Biodisponibilidade } \\
\text { relativa }(\%)\end{array}$ \\
\hline $\begin{array}{l}0,3 \\
0,4 \\
\end{array}$ & $\begin{array}{l}3,55 \\
4,86 \\
\end{array}$ & $\begin{array}{l}\text { Fosfato } \\
772 \\
819 \\
\end{array}$ & $\begin{array}{c}\text { defluorizado } \\
778 \\
815 \\
\end{array}$ & 99,86 \\
\hline $\begin{array}{l}0,3 \\
0,4\end{array}$ & $\begin{array}{l}3,65 \\
5,18\end{array}$ & $\begin{array}{l}\text { Fosfato } \\
746 \\
833 \\
\end{array}$ & $\begin{array}{c}\text { monocálcico B } \\
780 \\
823\end{array}$ & 98,43 \\
\hline $\begin{array}{l}0,3 \\
0,4\end{array}$ & $\begin{array}{l}3,74 \\
5,17\end{array}$ & $\begin{array}{l}\text { Fosfat } \\
784 \\
816\end{array}$ & $\begin{array}{c}\text { o bicálcico A } \\
783 \\
823\end{array}$ & 99,64 \\
\hline $\begin{array}{l}0,3 \\
0,4\end{array}$ & $\begin{array}{l}3,54 \\
5,05\end{array}$ & $\begin{array}{l}\text { Fosfat } \\
749 \\
829\end{array}$ & $\begin{array}{c}\text { o bicálcico B } \\
777 \\
820\end{array}$ & 98,75 \\
\hline $\begin{array}{l}0,3 \\
0,4 \\
\end{array}$ & $\begin{array}{l}3,62 \\
5,10 \\
\end{array}$ & $\begin{array}{l}\text { Fosfat } \\
760 \\
817\end{array}$ & $\begin{array}{c}\text { o bicálcico C } \\
779 \\
821 \\
\end{array}$ & 98,54 \\
\hline
\end{tabular}

\section{Conclusões}

1. Todos os fosfatos avaliados demonstram resultados de desempenho e de mineralização óssea satisfatórios, desde que utilizados níveis adequados de fósforo disponível na ração.

2. As fontes de fósforo estudadas apresentam pequenas variações de biodisponibilidade relativa de fósforo entre si.

\section{Referências}

BORGES, F.M.O.; FURTADO, M.A.O.; VELOSO, J.A.F.; BAIÃO, N.C. Disponibilidade do fósforo de fontes inorgânicas para frangos de corte. Arquivos Brasileiros de Medicina Veterinária e Zootecnia, v.49, p.639-647, 1997.

BUTOLO, J.E. Qualidade de ingredientes na alimentação animal. Campinas: Colégio Brasileiro de Alimentação Animal, 2002. 430p.

CORTELAZZI, C.Q.L. Fósforo disponível para frangos de corte em fosfatos para alimentação animal. 2006. 62p. Dissertação (Mestrado) - Universidade de São Paulo, Pirassununga.

DUARTE, H.C.; GRAÇA, D.S.; BORGES, F.M.O.; DI PAULA, O.J. Comparação de métodos in vitro para determinação da biodisponibilidade de fósforo. Arquivo Brasileiro de Medicina Veterinária e Zootecnia, v.55, p.80-84, 2003.

FERNANDES, J.I.; LIMA, F.R.; MENDONÇA JUNIOR, C.X.; MABE, I.; ALBUQUERQUE, R.; LEAL, P.M. Relative bioavailability of phosphorous in feed and agricultural phosphates for poultry. Poultry Science, v.78, p.1729-1736, 1999.

FERREIRA, D.F. Sistema de análises de variância para dados balanceados. Lavras: Ufla, 2000.

FURTADO, M.A.O. Determinação da biodisponibilidade de fósforo em suplementos de fósforo para aves e suínos. 1991. 60p. Dissertação (Mestrado) - Universidade Federal de Minas Gerais, Belo Horizonte.

GARCIA, A.R.; BATAL, A.B.; DALE, N.M. Biological availability of phosphorous sources in prestarter and starter diets for broiler chicks. Journal of Applied Poultry Research, v.15, p.518-524, 2006.

GARZILLO, J.M.F. Parâmetros biológicos usados na avaliação da biodisponibilidade do fósforo para frangos de corte em fosfatos comerciais e em fosfatos de rocha. 1996. 120p. Dissertação (Mestrado) - Universidade de São Paulo, São Paulo.

GILLIS, M.B.; NORRIS, L.C.; HEUSER, G.F. Studies on the biological value of inorganic phosphates. Journal of Nutrition, v.52, p.115-125, 1954.

GOMES, P.C.; GOMES, M.F.M.; ALBINO, L.F.T.; FIALHO, F.B.; LIMA, G.J.M.M.; FIGUEIREDO, E.A.P. Exigência de fósforo disponível para frangos de corte nas fases de crescimento e terminação. Revista da Sociedade Brasileira de Zootecnia, v.23, p.615-622, 1994.

LIMA, F.R.; MENDONÇA JUNIOR, C.X.; ALVAREZ, J.C.; GARZILLO, J.M.; GHION, E.; LEAL, P.M. Biological evaluations of commercial dicalcium phosphates as sources of available phosphorous for broiler chicks. Poultry Science, v.76, p.1707-1713, 1997.

NUNES, R.V.; BUTERI, C.B.; NUNES, C.V.G.; ALBINO, L.F.T.; ROSTAGNO, H.S. Fatores antinutricionais dos ingredientes destinados a alimentação animal. In: SIMPÓSIO SOBRE INGREDIENTES NA ALIMENTAÇÃO ANIMAL, 1., 2001, Campinas. Anais. Campinas: CBNA, 2001. p.235-272.

ROSTAGNO, H.S.; ALBINO, L.F.T.; DONZELE, J.L.; GOMES, P.C.; OLIVEIRA, R.F. de; LOPES, D.C.; FERREIRA, A.S.; 
BARRETO, S.L. de T. Tabelas brasileiras para aves e suínos: composição de alimentos e exigências nutricionais. 2.ed. Viçosa: UFV, 2005. 186p.

RUNHO, R.C.; GOMES, P.C.; ROSTAGNO, H.S.; ALBINO, L.F.T.; LOPES, P.S.; POZZA, P.C. Exigência de fósforo disponível para frangos de corte machos e fêmeas de 1-21 dias de idade. Revista Brasileira de Zootecnia, v.30, p.187-196, 2001.

YAN, F.; KEEN, C.A.; ZHANG, K.Y.; WALDROUP, P.W. Comparison of methods to evaluate bone mineralization. Journal of Applied Poultry Research, v.14, p.492-498, 2005.

Recebido em 26 de março de 2008 e aprovado em 17 de setembro de 2008 